\title{
Enhancement in the Corrosion Resistance of Nanocrystalline Aluminium Coatings by Incorporation of Graphene Oxide
}

\author{
Punith Kumar M K ${ }^{1}$, Prajwal M Laxmeesha ${ }^{1}$, Santanu Ray ${ }^{2}$, Chandan Srivastava ${ }^{1 *}$ \\ ${ }^{1}$ Department of Materials Engineering, Indian Institute of Science, Bangalore, India \\ ${ }^{2}$ School of Environment and Technology, University of Brighton, Brighton, United Kingdom \\ *Corresponding author address: Department of Materials Engineering \\ Indian Institute of Science \\ Bangalore-560012, India \\ Email: csrivastava@iisc.ac.in \\ Phone: 91-80-22932834 \\ FAX: 91-080-2360 0472
}

\begin{abstract}
:
Non-aqueous electrolyte containing aluminium chloride $\left(\mathrm{AlCl}_{3}\right)$ and 1-ethyl-3methylimidazolium chloride $([\mathrm{EMIm}] \mathrm{Cl})$ topped with n-decane was used to electrodeposit aluminium $(\mathrm{Al})$ coating via chronoamperometric method at ambient atmosphere. Aluminiumgraphene oxide (Al-GO) composite coating was further obtained from the Al electrolytic bath by dispersing GO in it. GO was prepared by oxidation of high purity graphite. The $\mathrm{Al}$ deposition potential was noted by cyclic voltammetry (CV) method. Influence of GO on the morphology and microstructure of Al metal matrix was analysed by scanning electron microscopy (SEM), energy dispersive X-ray spectroscopy (EDS) and X-ray diffraction spectroscopy (XRD). Inclusion of GO into the Al matrix enhanced the coating compactness thus nullifying the surface defects which were observed for the pristine Al deposit. The texture co-efficient calculation showed that the addition of GO altered the growth texture from growth predominately along (002) plane for pure Al coating to growth predominantly along (111) and (022) plane for Al-GO composite coating. The morphological and microstructural changes occurred in the $\mathrm{Al}$ coating from $\mathrm{GO}$ incorporation influenced the anti-corrosion behaviour of the coatings. The electrochemical corrosion analysis by Tafel polarization and Impedance
\end{abstract}


Spectroscopy confirmed that the GO reinforced Al deposit possessed two-fold enhanced anticorrosive property than pure Al coating.

Keywords: Al electrodeposition; Graphene oxide; Corrosion; Coatings.

\section{Introduction}

Aluminium (Al) has found broad applications owing to its low density, better formability and anti-corrosion behaviour [1-5]. Generally, techniques associated with high temperature are used to deposit aluminium on other substrates [6-9]. Use of high temperature in these techniques may produce thermal stress in the coating or in the substrate materials, and it can also lead to formation of undesirable intermetallics at the metal and coating interfaces $[10,11]$. In comparison with the above-mentioned deposition techniques, the electrodeposition technique offers significant advantages like, low cost, low energy utilization, simple process with good control over the deposition parameters to engineer the microstructure, morphology and thickness of the deposited layer [12, 13].

Electrodeposition of $\mathrm{Al}$ in aqueous electrolytes counters the water dissociation problem before the deposition of $\mathrm{Al}$, hence a non-aqueous electrodeposition route is appropriate for $\mathrm{Al}$ deposition [12]. Exploitation of room temperature ionic liquids [RTILs] as electroactive media for $\mathrm{Al}$ electrodeposition process are favoured because of their better ionic conductivity, broad electrochemical potential range and their ability to dissolve the metal salts [14-16]. The chloroaluminate ionic liquid system formed from 1-ethyl-3-methylimidazolium chloride ([EMIm]Cl) with $\mathrm{AlCl}_{3}$ is largely used in $\mathrm{Al}$ deposition process because of its ease in operation at room temperature [16-19]. Literature suggest that the change in the deposition parameters or the composition of the electrolytes greatly influence the surface morphology, microstructure and corrosion resistance properties of the $\mathrm{Al}$ deposit [16-19]. 
The enhancement of mechanical properties of Al materials has been achieved by incorporating the carbon allotropes like multiwalled carbon nano tubes (MWCNT's), graphene and graphene oxide layers by means of mechanical, thermal and electrochemical process [2024]. Given the interesting mechanical properties achieved by Al-graphene/graphene oxide composites, based on literature survey, there is no report yet on the influence of graphene oxide/carbon allotrope addition on the corrosion behaviour of Al coatings. Because, the incorporation of $\mathrm{G}$ and $\mathrm{GO}$ to the metal coatings $[25,26]$ significantly enhances the life time of the coatings in corrosive environments due to the chemical inertness of G/GO and resistance to the corrosive fluid penetration through them [27, 28].

In the present study, non-aqueous, ionic liquid electrolyte containing $\mathrm{Al}$ ions and dispersed GO was used to deposit $\mathrm{Al}-\mathrm{GO}$ electrochemically on copper $(\mathrm{Cu})$ substrate. It is shown that the addition of GO to the Al matrix significantly enhances the anticorrosion property of the Al coating.

\section{Experimental}

Graphene oxide was prepared using the modified Hummer's process given in our previous report [29]. The stable brown coloured dispersion in de-ionised water revealed the successful oxidation of graphite to from graphene oxide. Further, the XRD peak at $2 \theta$ value of $11.2^{\circ}$ corresponds to the characteristic $\left(\begin{array}{lll}0 & 0 & 1\end{array}\right)$ plane of GO sheets with interlayer spacing of $0.787 \mathrm{~nm}$ which is broader than the d-spacing value of graphitic ( 00 1) plane i.e., $0.34 \mathrm{~nm}$ [29]. The obtained UV-vis spectrum of GO shows a maximum absorption peak at $\lambda_{\max } 230 \mathrm{~nm}$ which represents the $\pi \rightarrow \pi^{*}$ transition of aromatic $\mathrm{C}-\mathrm{C}$ and $\mathrm{C}=\mathrm{C}$ bond of carbon in graphene oxide [30]. Also, the observed shoulder peak at $\lambda$ value of $297 \mathrm{~nm}$ represents the $\mathrm{n} \rightarrow \pi^{*}$ transition of the carbonyl groups $(\mathrm{C}=\mathrm{O})$ existing in the graphene oxide [30] (Supplementary XRD, UV-vis 
spectra and SEM image of GO are presented in Fig. S1). These results confirmed the successful oxidation of graphite to form graphene oxide sheets.

$\mathrm{AlCl}_{3}$ and $([\mathrm{EMIm}] \mathrm{Cl})$ were used in $60: 40 \mathrm{~mol} \%$ ratio respectively in the electrolytic bath. The ionic solution was prepared under nitrogen atmosphere at room temperature by continuously stirring the salts causing a highly exothermic reaction. The as-prepared ionic liquid was brown coloured viscous fluid. For producing Al-GO composite coating, $50 \mathrm{mg}$ of GO powder was dispersed in the $50 \mathrm{ml}$ of ionic liquid by thoroughly stirring the mixture for 1 hour under nitrogen atmosphere. A brownish-black solution was obtained, indicating GO dispersion in the solution. A few drops of decane were added along the walls of the beaker after the mixture cooled down to protect the ionic liquid from exposure to the atmosphere when the mixture was removed from the nitrogen atmosphere. Appropriately cut sheets of aluminium $(45 \times 25 \times 0.5 \mathrm{~mm})$ and copper $(45 \times 15 \times 0.5 \mathrm{~mm})$ acting respectively as anode and cathode were dipped into the solution after standard surface preparation procedure was followed. Another thin piece of aluminium was dipped in close proximity to the cathode as the reference electrode to complete the three-electrode electrochemical cell. All the electrodes were dried and stored under nitrogen atmosphere to make them free from water/moisture. The electrochemical experiments were conducted using CHI 640E electrochemical workstation. An initial cyclic voltammetry was conducted in order to determine the $\mathrm{Al}$ reduction voltage and a thick aluminium coating was deposited on copper substrate using chronoamperometric technique.

ESEM Quanta-200 SEM instrument united with Energy Dispersive X-ray Spectroscopy (EDS) was employed to analyse the Al, Al-GO coating morphology and its chemical composition. X-pert pro $\mathrm{X}$-ray analyser with $\mathrm{Cu} \mathrm{K \alpha}$ radiation $(\lambda=0.154 \mathrm{~nm})$ source was employed to obtain XRD profiles of electrodeposited $\mathrm{Al}$ and $\mathrm{Al}-\mathrm{GO}$ coatings in order to analyse their microstructure and preferred orientation. The corrosion resistance property of the $\mathrm{Al}$ and $\mathrm{Al}-\mathrm{GO}$ coatings were tested in $3.5 \mathrm{wt} \% \mathrm{NaCl}$ aqueous electroactive media using $\mathrm{CHI}-$ 
$640 \mathrm{E}$ electrochemical workstation. The $\mathrm{Al}$ or $\mathrm{Al}-\mathrm{GO}$ deposits with $1 \mathrm{~cm}^{2}$ exposed area were served as working electrode, $1 \mathrm{M} \mathrm{Ag} / \mathrm{AgCl}$ and platinum plate electrodes were employed as reference and auxiliary electrode respectively. The electrochemical corrosion analysis tests were conducted after immersing the sample in the electroactive media for 60 min to attain the equilibrium potential and meanwhile measured the open circuit potential (OCP) of the respective working electrode.

X-ray photoelectron spectroscopy (XPS) analysis of coated samples (thin film geometry) after corrosion was carried out using an ESCALAB $250 \mathrm{Xi}$ system (Thermo Scientific, Waltham, MA, USA) equipped with a monochromated Al $\mathrm{K} \alpha \mathrm{X}$-ray source (at $1486.6 \mathrm{eV}$ ) along with a MAGCISTM dual beam ion source and based at the Surface Analysis Laboratory, University of Brighton, UK. Uniform charge neutralization was provided by multimode electrostatic flood gun. XPS analysis spot size of 900x900 $\mu^{2}$ was defined by the microfocused X-ray source on flat $\mathrm{Cu}$ substrates coated with $\mathrm{Al}$ and Al-GO coating. Full survey scans (step size $1 \mathrm{eV}$, pass energy $150 \mathrm{eV}$, dwell time $50 \mathrm{~ms}$ and 5 scans) and narrow scans (step size $0.1 \mathrm{eV}$, pass energy $20 \mathrm{eV}$, dwell time $100 \mathrm{~ms}$ and 10 scans) of the $\mathrm{Al} 2 \mathrm{p}$ (binding energy, $\mathrm{BE} \sim 75 \mathrm{eV}), \mathrm{C} 1 \mathrm{~s}(\mathrm{BE} \sim 285 \mathrm{eV}), \mathrm{Cu} 2 \mathrm{p}(\mathrm{BE} \sim 933 \mathrm{eV})$ and $\mathrm{O} 1 \mathrm{~s}(\mathrm{BE} \sim 531 \mathrm{eV})$ were acquired from four separate regions on each sample. All XPS data were analysed using Thermo Advantage Software (Version 5.952) using a smart background.

\section{Results and Discussion}

\subsection{Electrochemical deposition of Al and Al-GO coatings: Cyclic Voltammetry and Chronoamperometry}

To understand the aluminium deposition potential on the copper substrate, cyclic voltammograms were recorded on the $\mathrm{Cu}$ substrate from $+1.2 \mathrm{~V}$ to $-1.0 \mathrm{~V}$ with $10 \mathrm{mV} / \mathrm{s}$ scan rate, the potential sweep started from $+1.2 \mathrm{~V}$ to cathodic direction and reversed at $-1.0 \mathrm{~V}$. Fig. 1 represents the cyclic voltammograms of $\mathrm{AlCl}_{3}-[\mathrm{EMIm}] \mathrm{Cl}$ and $\mathrm{AlCl}_{3}-([\mathrm{EMIm}] \mathrm{Cl})-\mathrm{Graphene}$ 
oxide. During the cathodic voltage scan, a peak $\left(\mathrm{d}_{\mathrm{Cu}}\right)$ can be observed at $+0.5 \mathrm{~V}$, which appears due to the dissolution of $\mathrm{Cu}$ in the electrolyte [31] The $\mathrm{AlCl}_{3} /[\mathrm{EMIm}] \mathrm{Cl}$ ionic liquid is a Lewis acid when the molar ratio is greater than ' 1 ' and under acidic condition Al deposition occurs through the reduction of $\mathrm{Al}_{2} \mathrm{Cl}_{7}^{-}$electroactive species following the given reaction $[16,18]$

$$
4 \mathrm{Al}_{2} \mathrm{Cl}_{7}^{-}+3 \mathrm{e}^{-} \rightarrow \mathrm{Al}+7 \mathrm{AlCl}_{4}^{-}
$$

The reduction of $\mathrm{Al}$ in bulk on the $\mathrm{Cu}$ working electrode starts at $-0.2 \mathrm{~V}$ for both $\mathrm{Al}$ and $\mathrm{Al}-\mathrm{GO}$ electrolytic solution. The cathodic current peak $\mathrm{I}_{\mathrm{c}}$, corresponding to the reduction of $\mathrm{Al}^{3+}$ to $\mathrm{Al}$ appears at $-0.55 \mathrm{~V}$ (voltage corresponds to cathodic current peak - $\mathrm{E}_{\mathrm{Ic}}$ ) for pure Al electrolytic bath. However, the $\mathrm{E}_{\mathrm{Ic}}$ shifted towards more negative for Al-GO electrolyte. This shift in the peak potential or cathodic polarization is because of the adsorption of graphene oxide on the cathode active sites. The peak $I_{a}$ represents the oxidation of bulk aluminium where aluminium is entirely stripped, the peak potential ( $\mathrm{E}_{\mathrm{Ia}}$ ) for the oxidation/stripping of bulk aluminium is $+0.2 \mathrm{~V}$ for pure $\mathrm{Al}$, but the $\mathrm{E}_{\mathrm{Ia}}$ value for stripping of $\mathrm{Al}$ from $\mathrm{Al}-\mathrm{GO}$ coating is $+0.6 \mathrm{~V}$. The positive shift in the oxidation potential of $\mathrm{Al}$ for $\mathrm{Al}-\mathrm{GO}$ system suggests that, significantly more energy is required to strip/oxidise the bulk $\mathrm{Al}$ from $\mathrm{Al}-\mathrm{GO}$ coating than pure $\mathrm{Al}$ coating.

Based on the $\mathrm{Al}$ reduction behaviour observed in the cyclic voltammograms, initially the chronoamperometric experiments were carried out at different potentials i.e., $-0.25 \mathrm{~V}$, $0.3 \mathrm{~V},-0.35 \mathrm{~V},-0.375$ and $-0.4 \mathrm{~V}$. Upon comparing the coatings from all the mentioned potentials, it was observed that the coating at $-0.375 \mathrm{~V}$ produced the best adhesion and surface finishing. Hence, the $\mathrm{Al}$ and $\mathrm{Al}-\mathrm{GO}$ composite coating deposition was carried out at $-0.375 \mathrm{~V}$ for $3 \mathrm{hrs}$ to obtain the thick coating to study the corrosion resistance performance of $\mathrm{Al}$ and AlGO coating against aggressive media. The current-time transients attained from the potentiostatic electrodeposition method at $0.375 \mathrm{~V}$ are given in Fig. 2. As observed in the current-time transients, the deposition current is high at the beginning of the deposition process because of the formation of $\mathrm{Al}$ nuclei which leads to swift deposition of $\mathrm{Al}$ on copper substrate 
and the subsequent decrease in current is due to the formation of weak aluminium ions layer on the cathode $[18,19]$ Further increase in the deposition current is due to the Al nucleation growth [18, 19]. The Al-GO deposition transient curves showed more deposition current compared to pure $\mathrm{Al}$ deposition, this may be due to the availability of more surface area for $\mathrm{Al}$ nucleation from incorporated GO sheets.

\subsection{Characterization of coatings}

Representative SEM micrograph of $\mathrm{Al}$ and Al-GO electrodeposited samples are depicted in Fig. 3A and 3B. The pure Al coating showed non-compact globular morphology due to growth of columnar structure with considerable gap between the columns. Addition of GO to the growing $\mathrm{Al}$ metal matrix significantly altered the surface morphology, which is clearly noticeable in Fig. 3B. The morphology of Al-GO coating is flat, uniform and compact in nature. The SEM-cross section micrographs of $\mathrm{Al}$ and Al-GO coatings are given in Fig. 3C and $3 \mathrm{D}$, the cross-section images revealed that the pure $\mathrm{Al}$ coating is flaky because of the lack of compactness, but the GO reinforcement enhances the compactness of the Al coating. The measured thickness of $\mathrm{Al}$ coatings from SEM cross-sectional analysis is on average $15.4 \mu \mathrm{m}$ and $16.6 \mu \mathrm{m}$ for pure $\mathrm{Al}$ and Al-GO coatings respectively. The observed increase in the deposition thickness of Al-GO coating may be due to the enhancement in the deposition rate caused by the GO incorporation, it can be observed in current-transient curves as there is an increase in deposition current for Al-GO coating.

Compositional measurement of $\mathrm{Al}$ and $\mathrm{Al}-\mathrm{GO}$ coatings from EDS analysis showed that Al coating contained $84.18 \mathrm{wt} \% \mathrm{Al}, 5.21 \mathrm{wt} \% \mathrm{C}, 2.24 \mathrm{wt} \% \mathrm{O}$ and $8.88 \mathrm{wt} \% \mathrm{Cl}$. The $\mathrm{Cl}, \mathrm{O}$ and $\mathrm{C}$ impurities in pure Al coating were from the ionic liquid [13]. The incorporation of GO into the growing $\mathrm{Al}$ metal matrix not only influenced the surface morphology but also significantly changed the elemental composition. The observed elemental composition of Al-GO composite 
coating was $86.19 \mathrm{wt} \% \mathrm{Al}, 8.50 \mathrm{wt} \% \mathrm{C}, 4.54 \mathrm{wt} \% \mathrm{O}$ and $0.77 \mathrm{wt} \% \mathrm{Cl}$. The increase in $\mathrm{C}$ and $\mathrm{O}$ content in the Al-GO coating indicated the incorporation of graphene oxide into the metal matrix.

To determine the crystallite size and preferred orientation of aluminium crystal planes, XRD patterns for $\mathrm{Al}$ and Al-GO coatings were obtained and are depicted in Fig. 4. Average aluminium crystallite size calculated from the Scherrer equation for pure Al coating was $32 \mathrm{~nm}$ and for Al-GO coating was $53 \mathrm{~nm}$. The micrographs given in Fig. 3 reveals the significant morphological changes in Al-GO composite coating compared to pure Al deposit. The morphological change infer that the incorporation of graphene oxide sheets affects the electrocrystallization process which may also change the preferential orientation of aluminium crystal plane in Al-GO composite coating. Hence, the texture coefficient was determined from XRD data using equation (1) [26] to identify the preferential orientation of the crystal growth.

$$
T_{c}(h k l)=\frac{I(h k l)}{\sum I(h k l)} \times \frac{\sum I_{o}(h k l)}{I_{0}(h k l)}
$$

Where, I(hkl) represents the peak intensity of the coatings, $\Sigma \mathrm{I}(\mathrm{hkl})$ is the sum of intensities of the individual peaks and 'o' refers to the standard aluminium sample [26]. The calculated texture coefficient for $\mathrm{Al}$ and Al-GO deposits are given in Fig. 5 and it can be observed that, aluminium crystallites are oriented parallel to $\left(\begin{array}{lll}1 & 1 & 1\end{array}\right),\left(\begin{array}{lll}0 & 0 & 2\end{array}\right)$ and $\left(\begin{array}{lll}0 & 2 & 2\end{array}\right)$ for both Al and AlGO coatings. However, majority of aluminium crystallites are grown parallel to the $\left(\begin{array}{lll}0 & 0 & 2\end{array}\right)$ plane in pure $\mathrm{Al}$ coating, but in $\mathrm{Al}-\mathrm{GO}$ composite coating, the $\mathrm{Al}$ crystal growth increased in (llll 111$)$ and $\left(\begin{array}{lll}0 & 2 & 2\end{array}\right)$ direction. These observations infer that the inclusion of graphene oxide into the Al metal matrix significantly influenced the surface morphology along with the texture of the $\mathrm{Al}$ coating.

\subsection{Electrochemical corrosion analysis}


The stability of the Al and Al-GO coatings against corrosive environment was tested by potentiodynamic polarization and EIS methods and also used to quantify the corrosion parameters.

The Tafel polarization plots were recorded in $3.5 \% \mathrm{NaCl}$ electrolyte media by polarizing the working electrode $\pm 200 \mathrm{mV}$ from their respective OCP value. Fig. 6 shows the Tafel polarization plots and the calculated corrosion parameters like corrosion potential $\left(\mathrm{E}_{\mathrm{corr}}\right)$, corrosion current $\left(\mathrm{I}_{\text {corr }}\right)$ and corrosion rate $(\mathrm{CR})$ are tabulated in Table 1. The Tafel curve of Al-GO composite coating is shifted towards less negative potential value compared to pure $\mathrm{Al}$ coating. The corrosion potential $\left(\mathrm{E}_{\text {corr }}\right)$ value for $\mathrm{Al}$ and $\mathrm{Al}-\mathrm{GO}$ coating was $-0.754 \mathrm{~V}$ and $0.716 \mathrm{~V}$ respectively. Al-GO composite coating possessed less negative corrosion potential compared to pure $\mathrm{Al}$ coating corrosion potential. This indicates that, considerably high voltage is required to corrode the $\mathrm{GO}$ incorporated $\mathrm{Al}$ coating. Al-GO composite coating have nobler nature towards the aggressive environment. The measured corrosion current ( $\left.\mathrm{I}_{\text {corr }}\right)$ value for $\mathrm{Al}$ and Al-GO coating was $24.38 \mu \mathrm{A} \mathrm{cm} \mathrm{cm}^{-2}$ and $9.63 \mu \mathrm{A} \mathrm{cm} \mathrm{cm}^{-2}$ respectively. The $\mathrm{I}_{\text {corr }}$ value for GO incorporated $\mathrm{Al}$ coating is considerably reduced compared to the $\mathrm{I}_{\text {corr }}$ value of pure $\mathrm{Al}$ coating. The quantitative corrosion parameter corrosion rate is directly proportional to $\mathrm{I}_{\text {corr }}$, hence the reduction in $\mathrm{I}_{\text {corr }}$ value for Al-GO composite coating suggests that, the GO embedded Al coated surface interaction with electroactive media is lesser when compared to pure $\mathrm{Al}$ coating. Al-GO coating corrodes at $60 \%$ slower rate when compared to the corrosion rate of pure Al deposit.

As seen in the Fig. 6, the Al-GO coating shown higher cathodic current density at the given potential compared to pure Al coating. But, Al-GO coating exhibited smaller anodic current density compared to Al coating. The oxidation of aluminium and evolution of hydrogen gas/oxygen reduction occurs at the anode and cathode respectively. The presence of carbonaceous material in the Al-GO composite coating may enhanced the hydrogen reduction 
rate on the working electrode, hence the cathodic current density is increased with lower cathodic Tafel slope value. However, the higher anodic Tafel slope value with decreased anodic corrosion current density of the Al-GO coating suggests that, the more potential is required to corrode $\mathrm{Al}$ from $\mathrm{Al}-\mathrm{GO}$ coating compared to potential required to liberate $\mathrm{Al}$ from GO free Al coating.

The fundamental objective of this paper is to investigate the efficiency of both $\mathrm{Al}$ and Al-GO on copper substrates as a corrosion protective layer. Standard XPS reference spectra of electrodeposited Al has been previously published [32] and for that reason, XPS analysis was carried out after $\mathrm{Al}$ and $\mathrm{Al}-\mathrm{GO}$ coated copper substrates underwent corrosive environment. As shown in the Table 2, underlying copper is exposed for the sample with pure Al coating, following exposure to the lab based corrosive media. As seen in the SEM micrographs, GO free Al coating have uneven surface with gaps and cracks, these surface heterogeneities increased after the corrosion process and led to considerable uncovered substrate which is responsible for the appearance of the copper in the XPS spectra as indicated in Table 2. Detection of relatively high amount of carbon is due to the fact that XPS only analyses top 10 $\mathrm{nm}$ of the surfaces which usually is contaminated with advantageous carbon. In this present case, the corrosion test provided ample opportunity to adsorb carbons on the top layer. XPS survey spectra was acquired after sputter cleaning the surface with cluster argon gun for $30 \mathrm{sec}$. Presence of copper provides the evidence of either cracks and or removal of pure aluminium coatings. In supporting information Fig. S2, comparison of $\mathrm{Cu} 2 \mathrm{p}$ spectra collected from $\mathrm{Al}$ and Al-GO coated copper substrates is shown. Although there is very minimal detection of $\mathrm{Cu}$ (below 0.1 atomic\%) in case of Al-GO coated substrates; the detected amount is absolutely low compared to the just Al coated sample. SEM investigation also illustrates the nature of the AlGO coatings that undoubtedly provided better corrosion protection than just Al coating. Near total disappearance of copper peaks in the GO incorporated $\mathrm{Al}$ coating could be due to its 
continuous, smooth and crack free finishing. These observations confirm that, the GO reinforced $\mathrm{Al}$ coatings are more anticorrosive and provides better protection to the substrate against the aggressive environment. Presence of GO could also be analysed from the XPS narrow scan spectra, as shown in the Fig. 7. Peak assignments were followed using NIST XPS Database. As shown in the Fig. 7a and 7b, sp2 hybridised C1s provides the evidence of the presence of GO on the sample Al-GO. Rest of the different carbon compounds are present due to the presence of advantageous carbons [33]. Comparison of elemental states by means of XPS narrow scan analysis of Al2p spectra between Al and Al-GO coating after corrosion could not be completed due to that fact that the binding energies of Al2p region coincides with $\mathrm{Cu} 3 \mathrm{p}$ region making it impossible to differentiate using standard XPS measurement. As Cu was exposed in the sample with just Al coating, corresponding Al2p peaks were influenced by the presence of electrons coming out from Cu3p regions. However, A12p XPS narrow scan data of Al-GO sample confirms the presence of $\mathrm{Al}_{2} \mathrm{O}_{3}$ and $\mathrm{AlOOH}$ on corroded Al-GO coatings; as shown in Fig. 7c. Fig.7d shows the narrow scan analysis of the exposed copper in AL coated samples, where $\mathrm{Cu}(\mathrm{I})$ and $\mathrm{Cu}(\mathrm{II})$ states were detected following exposure to corrosive media [34]. O1s narrow scan spectra revealed presence of oxides and hydroxides along with presence of carbon contaminations in cases of $\mathrm{Al}$ and $\mathrm{Al}-\mathrm{GO}$ coated copper substrates, as shown in Fig. 7e and 7f. Presence of aluminium oxyhydroxide $(\mathrm{AlOOH})$ and aluminium oxide as corrosion products on the surface acts like protecting layer against the corrosive media by separating the working electrode surface and the electrolyte and it is responsible for the inductive behaviour observed in the EIS corrosion analysis.

The electrochemical impedance behaviour of the $\mathrm{Al}$ and $\mathrm{Al}-\mathrm{GO}$ coatings was measured at their respective OCP values by applying the AC frequency from $100 \mathrm{kHz}$ to $100 \mathrm{mHz}$ at 6 points per decade frequency with a sinusoidal signal amplitude of $5 \mathrm{mV}$. The corrosion parameters from the EIS data were obtained by curve fitting the EIS data using ZSimpWin 3.21 
software. The measured EIS data for pure Al and Al-GO coatings are represented as typical Nyquist plots in Fig. 8 and as Bode plots in Fig. 9. The Nyquist plot of the Al and Al-GO coatings shows one definite capacitive loop sited above the zero of imaginary (-Z") axis which indicates the capacitive behaviour of the electrode (because of the $+90^{\circ}$ phase difference between current and voltage) $[34,35]$. Also, there is an initiation of other capacitive loop sited below the zero of imaginary (-Z") at lower frequency indicates the inductive behaviour of the sample (because of $-90^{\circ}$ phase difference between current and voltage) $[34,35]$. This impedance behaviour is more clearly appeared in the Bode plot. The observed inductive behaviour at low frequency is due to the non-stationary corrosion products adsorbed on the working electrode, however, in the present work the low frequency inductive loop is not well defined. In the $|\mathrm{Z}|$ vs $\log$ frequency bode plot, the impedance value for both the coatings initially increases but decreases at the low frequency range because of the inductive behaviour of the coatings. Also, negative phase angle can be seen in phase angle vs log frequency bode plots because of the inductive behaviour of the coatings. Hence, to understand the corrosion protection mechanism and to obtain the corrosion parameters, the experimentally obtained EIS data were curve fitted with the suitable electrical equivalent circuit (EEC) i.e., Randle circuit and it is given as inset in Fig. 8. The inductive element is not used in the EEC to curve fit the EIS data because the inductive loop is not well defined and the curve fitting of the inductive character observed in the present EIS data will not yield the appropriate information, hence the typical Randle circuit is used to fit the only capacitive loop [36]. The corrosion parameters attained from curve fitting of EIS data are tabulated in Table 3. To obtain precise fitting results the high frequency capacitance element (C) used in the EEC was substituted by constant phase element (CPE, Q). The impedance of the constant phase element is defined by the following equation

$Z(j \omega)=1 /(Q)^{1}(j \omega)^{n}$ 
In the above equation, $\mathrm{CPE}$ constant ' $Q$ ' with angular frequency ' $\omega$ ' where $\omega=2 \pi f$ (' $f$ ' is the frequency), $j$ is the imaginary unit and ' $n$ ' is the CPE exponent $(-1 \leq \mathrm{n} \leq 1)$. The CPE exponent ' $n$ ' determines the capacitance distribution. The value of $n=1$ for an ideal capacitor and it decreases with increased surface roughness/defects where non-uniform current distribution occurs [26].

In the used EEC, $\mathrm{R}_{\mathrm{s}}$ represents the solution resistance, the $\mathrm{RC}$ couple denotes the charge transfer resistance $R_{c t}$ and the double layer constant phase element $Q_{d l}$ (i.e., double layer capacitance which forms at the working electrode/electrolyte interface because of the adsorbed ions on the working electrode surface) $[35,36]$. The constant phase element exponent 'n' value obtained from EEC analysis is less than ' 1 ' and it may due to the surface roughness created from the adsorbed corrosion products on the working electrode. The pure Al coated surface exhibited higher $\mathrm{Q}_{\mathrm{dl}}$ value and low charge transfer resistance $\left(\mathrm{R}_{\mathrm{ct}}\right.$ - which is directly proportion to the corrosion resistance), which means pure $\mathrm{Al}$ coating is highly active towards the electrolyte media and therefore less corrosion resistant in nature. However, the $\mathrm{Q}_{\mathrm{d} l}$ value decreased for the GO reinforced $\mathrm{Al}$ coating and the Al-GO coating possessed two-fold increased charge transfer resistance $\left(R_{c t}\right)$ value than the $R_{c t}$ value of pure $A l$ coating. The decreased $\mathrm{Q}_{\mathrm{dl}}$ value with considerably high $\mathrm{R}_{\mathrm{ct}}$ value of Al-GO coating depicts that, Al-GO coating is highly resistive towards the corrosive media. Also, the absolute impedance value observed in bode plot is considerably higher for Al-GO coating compared to pure Al coating.

The compact and defect free surface morphology, microstructure and presence of GO layers in the $\mathrm{Al}$ coatings reduces the active contact between the coating and the electrolyte and the formed corrosion products layer on the Al-GO composite coatings also acts as protective layer against the corrosive media and the combined effect of these parameters enhanced the corrosion resistance property of the $\mathrm{GO}$ reinforced $\mathrm{Al}$ coating. 


\section{Conclusion:}

In conclusion, Al-GO composite coatings were successfully electro-deposited on copper substrate using chronoamperometric technique. Incorporation of GO into the $\mathrm{Al}$ matrix significantly enhanced the surface morphology. pure Al deposit surface has non-compact granular morphology with crevices and micro-holes which can behaves as active sites during the corrosion process. Incorporation of $\mathrm{GO}$ into the $\mathrm{Al}$ deposit alters the morphology making the coating defect free and compact in nature, hence the activity of Al-GO coated surface towards the electroactive media is considerably lowered. The GO incorporation also changed the preferred orientation of Al crystallites to $\left(\begin{array}{lll}1 & 1 & 1\end{array}\right)$ and $\left(\begin{array}{lll}0 & 2 & 2\end{array}\right)$ from $\left(\begin{array}{lll}0 & 0 & 2\end{array}\right)$ observed in the case of pure $\mathrm{Al}$ coating. $\mathrm{GO}$ embedded $\mathrm{Al}$ coating showed $60 \%$ reduction in corrosion current with two-fold increase in the charge transfer resistance. Al-GO coating unveiled significantly improved corrosion resistance than pure $\mathrm{Al}$ coating.

\section{Acknowledgements}

Authors acknowledge the research funding received from the CSIR Government of India. Authors would also like to acknowledge the funding received under Global Challenge Research Fund (GCRF) Business Case through the University of Brighton, UK.

\section{Appendix A. Supplementary data}

\section{References}

[1] Y. Liu, H. Liu and Z. Chen, Post-fire mechanical properties of aluminum alloy 6082-T6, Constr. Build. Mater. 196 (2019) 256-266.

[2] F.M. Mazzolani, 3D aluminium structures, Thin Walled Struct. 61 (2012), pp. 258-266.

[3] X. Tu, J. Zhang, M. Zhang, Y. Cai, H. Lang, G. Tian and Y. Wang, Electrodeposition of aluminium foils on carbon electrodes in low temperature ionic liquid, RSC Adv. 7 (2017) 14790-14796.

[4] J-M. Ju, G. Wang and K-H. Sim, Facile synthesis of graphene reinforced Al matrix 
composites with improved dispersion of graphene and enhanced mechanical properties, J. Alloys Compd. 704 (2017) 585-592.

[5] K. Song, I. Kim, S. Bang, J-Y. Jung and Y. Nam, Corrosion resistance of water repellent aluminum surfaces with various wetting morphologies, Appl. Surf. Sci. 467-468 (2019) 1046-1052.

[6] O. Sarikaya, S. Anik, S. Aslanlar, S. C. Okumus and E. Celik, Al-Si/B 4 C composite coatings on Al-Si substrate by plasma spray technique, Mater. Des. 28 (2007) 24432449.

[7] W-J. Cheng and C-J. Wang, Growth of intermetallic layer in the aluminide mild steel during hot-dipping. Surf. Coat. Technol. 204 (2009) 824-828.

[8] J. Romanowska, Aluminum diffusion in aluminide coatings deposited by the CVD method on pure nickel, Calphad 44 (2014) 114-118.

[9] N. Koura, H. Nagase, A. Sato, S. Kumakura, K. Takeuchi, K. Ui, T. Tsuda and C.K. Loong, Electroless Plating of Aluminum from a Room-Temperature Ionic Liquid Electrolyte, J. Electrochem. Soc. 155(2) (2008) D155-157.

[10] M.J. Hollamby, D. Borisova, H. Mohwald and D. Shchukin, Porous 'Ouzo-effect' silicaceria composite colloids and their application to aluminium corrosion protection, Chem. Commun. 48 (2012) 115-117.

[11] M. Zhang, V. Kamavarum and R.G. Reddy, New Electrolytes for Aluminum Production: Ionic Liquids, JOM. 55 (2003) 54-57.

[12] P.V. Suneesh, T.G.S. Babu and T. Ramachandran, Electrodeposition of aluminium and aluminium-copper alloys from a room temperature ionic liquid electrolyte containing aluminium chloride and triethylamine hydrochloride, Int. J. Miner. Metall. Mater. 20 (2013) 909-916.

[13] Y. Hou, R. Li and J. Liang, Simultaneous electropolishing and electrodeposition of aluminum in ionic liquid under ambient conditions, Appl. Surf. Sci. 434 (2018) 918921.

[14] D. Pradhan and R.G. Reddy, Mechanistic study of Al electrodeposition from EMIC-AlCl 3 and BMIC-AlCl$l_{3}$ electrolytes at low temperature, Mater. Chem. Phys.143 (2014) 564569.

[15] J-K. Chang, S-Y. Chen, W-T. Tsai, M-J. Deng and I-W. Sun, Electrodeposition of aluminum on magnesium alloy in aluminum chloride $\left(\mathrm{AlCl}_{3}\right)-1$-ethyl-3methylimidazolium chloride (EMIC) ionic liquid and its corrosion behaviour, Electrochem. Commun. 9 (2007) 1602-1606.

[16] T. Jiang, M.J.C. Brym, G. Dube, A. Lasia and G.M. Brisard, Electrodeposition of aluminium from ionic liquids: Part I-electrodeposition and surface morphology of aluminium from aluminium chloride $\left(\mathrm{AlCl}_{3}\right)$-1-ethyl-3-methylimidazolium chloride ([EMIm]Cl) ionic liquids, Surf. Coat. Technol. 201 (2006) 1-9. 
[17] A. Bakkar and V.A. Neubert, A new method for practical electrodeposition of aluminium from ionic liquids, Eelectrochem. Commun. 51 (2015) 113-116.

[18] A. Bakkar and V. Neubert, Electrodeposition and corrosion characterisation of microand nano-crystalline aluminium from $\mathrm{AlCl} 3 / 1$-ethyl-3-methylimidazolium chloride ionic liquid, Electrochim. Acta 103 (2013) 211-218.

[19] J. Tang and K. Azumi, Optimization of pulsed electrodeposition of aluminum from $\mathrm{AlCl}_{3}$-1-ethyl-3-methylimidazolium chloride ionic liquid, Electrochim. Acta 56 (2011) 1130-1137.

[20] Z.W. Zhang, Z.Y. Liu, B.I. Xiao, D.R. Ni and Z.Y. Ma, High efficiency dispersal and strengthening of graphene reinforced aluminum alloy composites fabricated by powder metallurgy combined with friction stir processing, Carbon 135 (2018) 215-223.

[21] S.E. Shin, H.J. Choi, J.H. Shin and D.H. Bae, Strengthening behavior of few-layered graphene/aluminum composites, Carbon 82 (2015) 143-151.

[22] Y. Wu and G-Y. Kim, Carbon nanotube reinforced aluminum composite fabricated by semi-solid powder processing, J. Mater. Process Technol. 211 (2011) 1341-1347.

[23] H. Asgharzadeh and M. Sedigh, Synthesis and mechanical properties of Al matrix composites reinforced with few-layer graphene and graphene oxide, J. Alloys Compd. 728 (2017) 47-62.

[24] N. Li, M. Xu, T. Xia, X. Ruan, S. Song and H. Ma, Preparation and mechanical property of electrodeposited Al-graphene composite coating, Mater. Des. 111 (2016) 522-527.

[25] M.K.P. Kumar, M.P. Singh and C. Srivastava, Electrochemical behavior of Zn-graphene composite coatings, RSC Adv. 5 (2015) 25603-25608.

[26] A. Gupta and C. Srivastava, Enhanced corrosion resistance by $\mathrm{SnCu}$-graphene oxide composite coatings, Thin Solid Films 669 (2019) 85-95.

[27] D. Prasai, J.C. Tuberquia, R.R. Harl, G.K. Jennings and K.I. Bolotin, Graphene: Corrosion-Inhibiting Coating, ACS Nano 6 (2012) 1102-1108.

[28] D. Kang, J.Y. Kwon, H. Cho, J-H. Sim, H.S. Hwang, C.S. Kim, Y.J. Kim, R.S. Ruoff and H.S. Shin, Oxidation Resistance of Iron and Copper Foils Coated with Reduced Graphene Oxide Multilayers, ACS Nano 6 (2012) 7763-7769.

[29] M.Y. Rekha, A. Kamboj and C. Srivastava, Electrochemical behavior of SnNi-graphene oxide composite coatings, Thin Solid Films 653 (2018) 82-92.

[30] D.C. Marcano, D.V. Kosynkin, J.M. Berlin, A. Sinitskii, Z. Sun, A. Slesarev, L.B. Alemany, W. Lu and J.M. Tour, Improved Synthesis of Graphene Oxide, ACS Nano 4 (2010) 4806-4814.

[31] A.B. Waqar, Exploration of Electrodeposition of Aluminum-Nickel Alloys and 
Multilayers in Organic Chloroaluminate Ionic Liquids. University of South Florida. Graduate Thesis and Dissertations. 2014.

[32] Z.W. Zhao, B.K. Tay, G.Q. Yu, D.H.C. Chua, S.P. Lau and L.K. Cheah, Optical properties of aluminium oxide thin films prepared at room temperature by off-plane filtered cathodic vacuum arc system, Thin Solid Films 447-448 (2004) 14-19.

[33] R.J.L. Welbourn, C.L. Truscott, M.W.A. Skoda, A. Zarbakhsh, S.M. Clarke, Corrosion and inhibition of copper in hydrocarbon solution on a molecular level investigated using neutron reflectometry and XPS, Corros. Sci. 115 (2017) 68-77.

[34] M. Keddam, C. Kuntz, H. Takenouti, D. Schuster and D. Zuili, Exfoliation corrosion of aluminium alloys examined by electrode impedance, Electrochim. Acta 42 (1997) 8797.

[35] R.R. Laleh, H. Savaloni, F. Abdi and Y. Abdi, Corrosion inhibition enhancement of Al alloy by graphene oxide coating in $\mathrm{NaCl}$ solution, Prog. Org. Coat. 127 (2019) 300307.

[36] A. Vicere, G. Roventi, C. Paoletti, M. Cabibbo and T. Bellezze, Corrosion Behavior of AA6012 Aluminum Alloy Processed by ECAP and Cryogenic Treatment, Metals 9 (2019) $408(1-13)$.

\section{Figure captions:}

Fig. 1. The cyclic voltammograms of $\mathrm{Cu}$ recorded at $10 \mathrm{mV} / \mathrm{s}$ scan rate in $\mathrm{AlCl}_{3}-([\mathrm{EMIm}] \mathrm{Cl})$ $(60: 40 \mathrm{~mol} \%)$ ionic liquid plating bath topped with decane to protect from air.

Fig. 2. Typical current-time transient curves of $\mathrm{Cu}$ during the Potentiostatic electrodeposition of $\mathrm{Al}$ from $\mathrm{AlCl}_{3}-([\mathrm{EMIm}] \mathrm{Cl})(60: 40 \mathrm{~mol} \%)$ ionic liquid electrolyte.

Fig. 3. Scanning Electron micrographs of (A) aluminium, (B) aluminium-GO electrodeposited surfaces and SEM cross-section images of (C) Al, (D) Al-GO coatings.

Fig. 4. X-ray diffractograms for $\mathrm{Al}$ and $\mathrm{Al}-\mathrm{GO}$ coatings obtained from $\mathrm{AlCl}_{3}-([\mathrm{EMIm}] \mathrm{Cl})$ $(60: 40 \mathrm{~mol} \%)$ ionic liquid electrolyte.

Fig. 5. Preferred orientation of aluminium crystallites in pure $\mathrm{Al}$ and $\mathrm{Al}-\mathrm{GO}$ composite coating.

Fig. 6. Potentiodynamic polarization curves recorded for $\mathrm{Al}$ and Al-GO coatings against $\mathrm{Ag} / \mathrm{AgCl}$ reference electrode in $3.5 \% \mathrm{NaCl}$ electroactive media.

Fig. 7. Carbon 1s (C1s) narrow scan spectra of (a) Al and (b) Al-GO sample with legends showing the corresponding peak assignments. Al2p narrow scan spectra (c) of Al-GO sample shows the presence of $\mathrm{Al}_{2} \mathrm{O}_{3}$ and $\mathrm{AlOOH}$. All peak assignment references are from NIST (The National Institute of Standards and Technology, USA) Database, which can be accessed free off charge. 
Fig. 8. Typical impedance Nyquist plots of $\mathrm{Al}$ and $\mathrm{Al}-\mathrm{GO}$ coatings recorded in $3.5 \% \mathrm{NaCl}$ corrosive media [line - measured data, symbol - simulated data]. The inset shows the electrical equivalent circuit used to simulate the EIS data to obtain electrochemical corrosion parameters.

Fig. 9. EIS Bode, $\log |\mathrm{Z}| \&$ phase angle vs log frequency plots of $\mathrm{Al}$ and $\mathrm{Al}-\mathrm{GO}$ coatings.

Fig. S1. (A) XRD profile (B) UV-Visible spectrum and (C) SEM micrograph for graphene oxide synthesized by modified Hummer's method. (Supplementary).

Fig. S2. Comparison of $\mathrm{Cu} 2 \mathrm{p}$ spectra collected from $\mathrm{Al}$ and Al-GO coated copper substrates. (Supplementary).

\section{Table captions:}

Table 1. Electrochemical corrosion parameters attained from Tafel polarization curves.

Table 2. XPS survey scan data of two samples (Al and Al-GO) after corrosion.

Table 3. Electrochemical corrosion data derived from EIS data simulation from electrical equivalent circuit. 


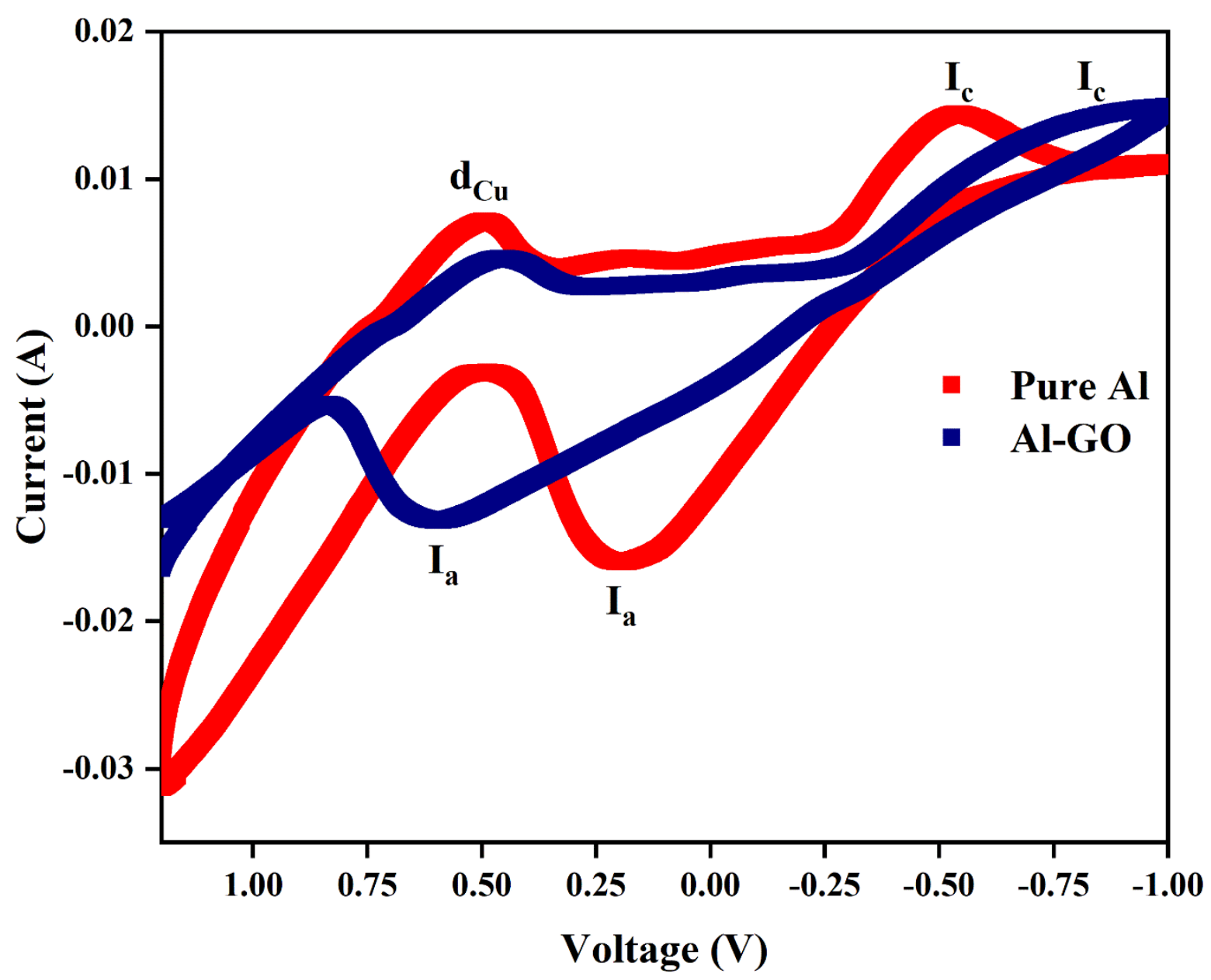

Fig. 1. The cyclic voltammograms of $\mathrm{Cu}$ recorded at $10 \mathrm{mV} / \mathrm{s}$ scan rate in $\mathrm{AlCl}_{3}-([\mathrm{EMIm}] \mathrm{Cl})$ $(60: 40 \mathrm{~mol} \%)$ ionic liquid plating bath topped with decane to protect from air. 


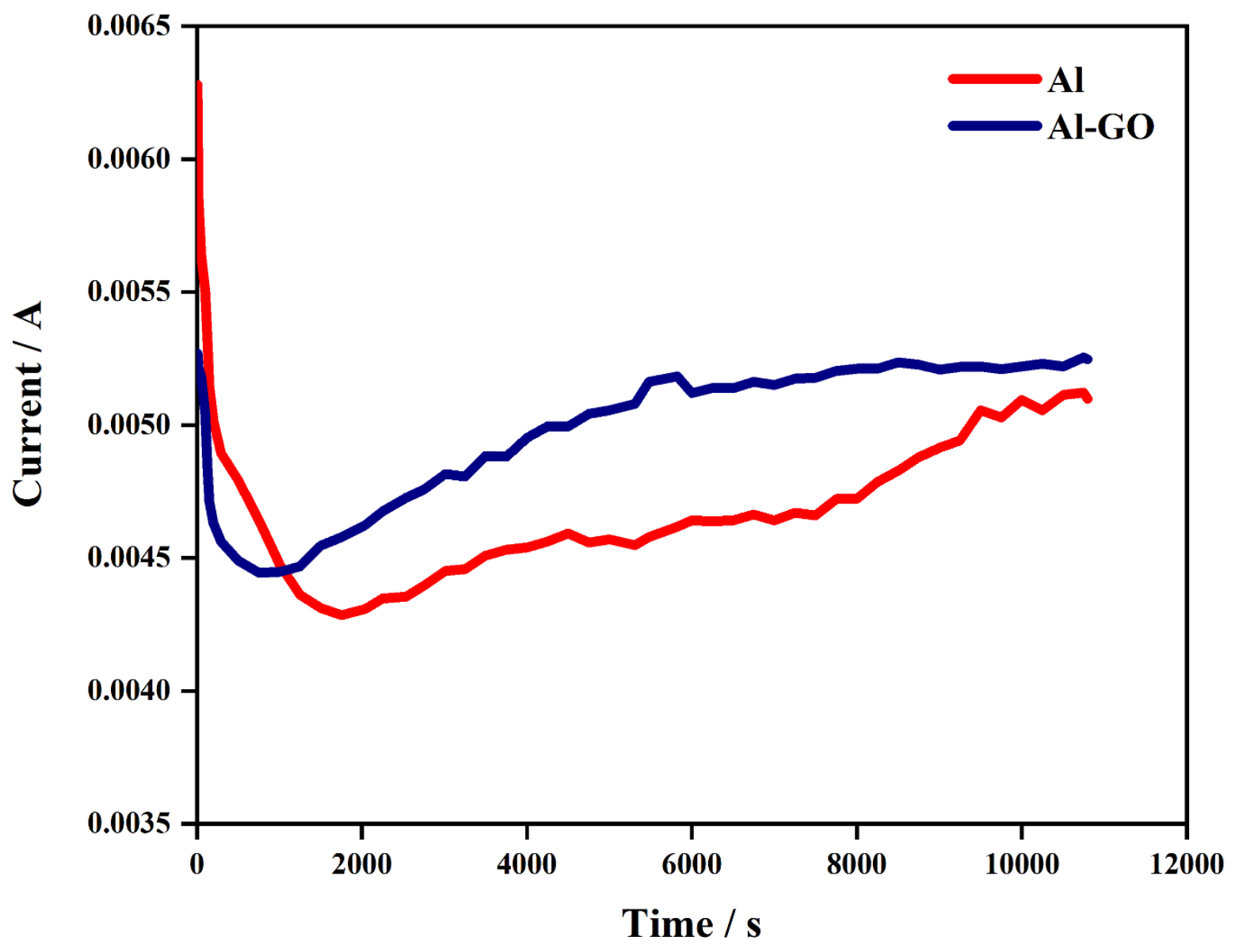

Fig. 2. Typical current-time transient curves of $\mathrm{Cu}$ during the Potentiostatic electrodeposition of $\mathrm{Al}$ from $\mathrm{AlCl}_{3}-([\mathrm{EMIm}] \mathrm{Cl})(60: 40 \mathrm{~mol} \%)$ ionic liquid electrolyte. 

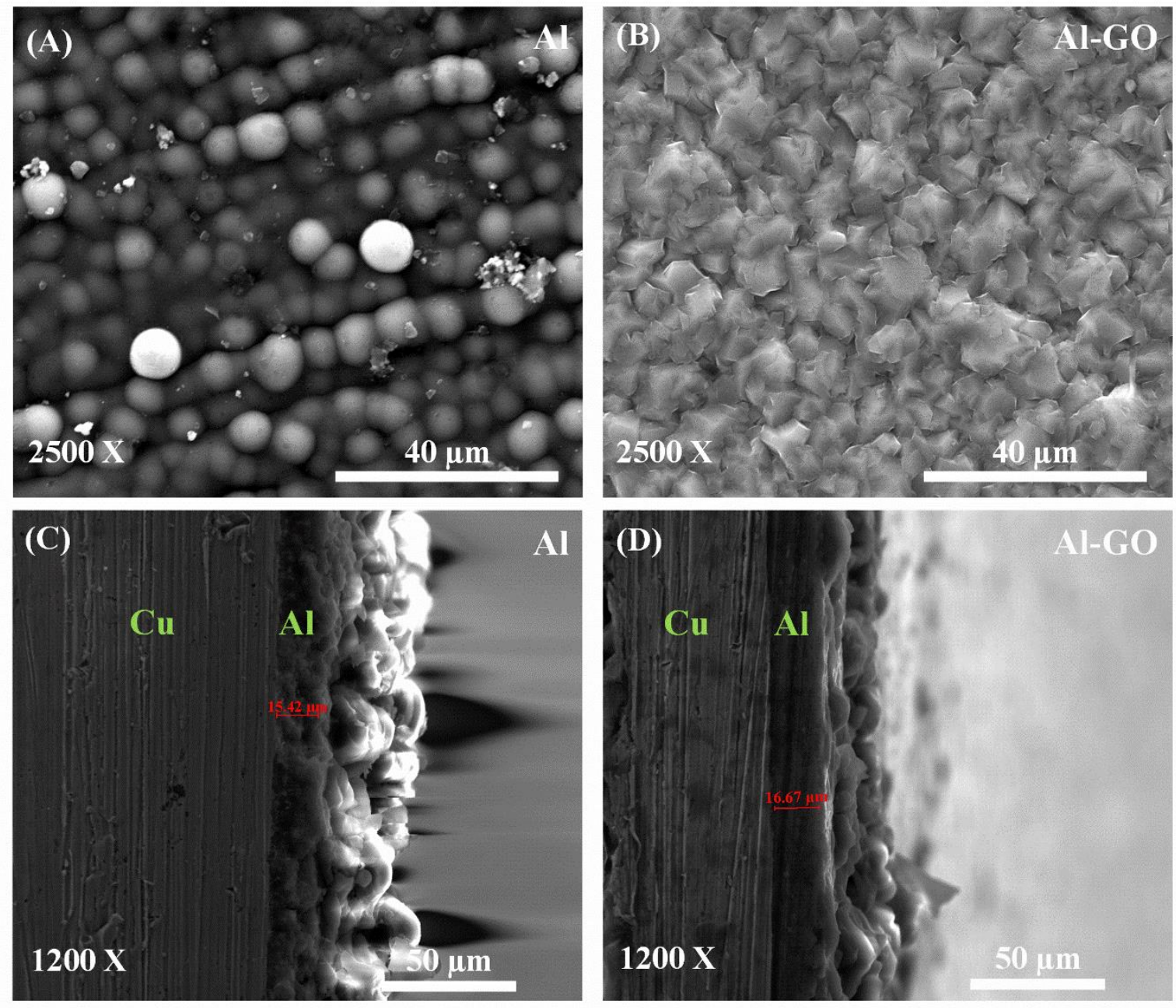

Fig. 3. Scanning electron micrographs of (A) aluminium, (B) aluminium-GO electrodeposited surfaces and SEM cross-section images of (C) Al, (D) Al-GO coatings. 


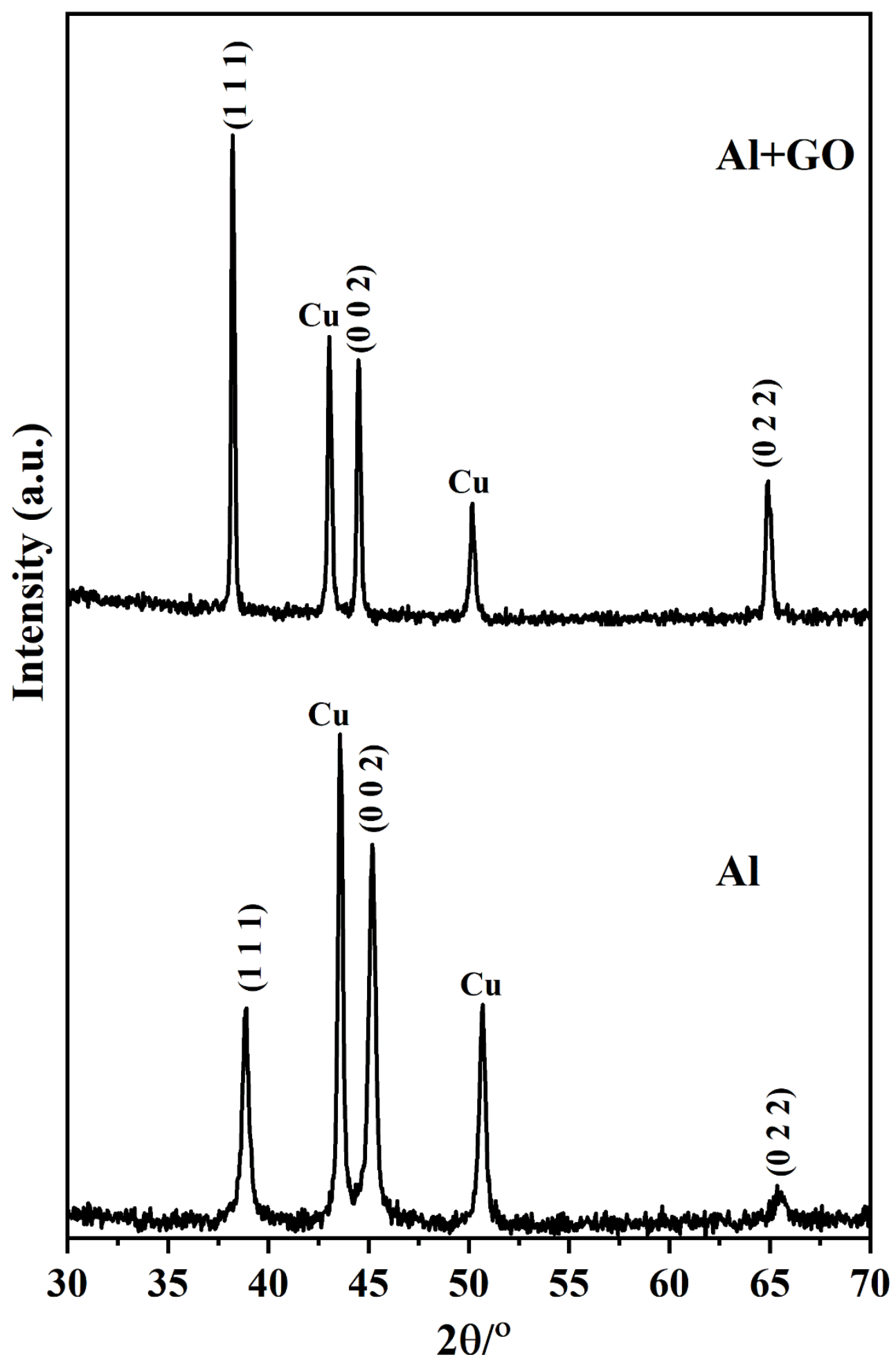

Fig. 4. X-ray diffractograms for $\mathrm{Al}$ and $\mathrm{Al}-\mathrm{GO}$ coatings obtained from $\mathrm{AlCl}_{3}-([\mathrm{EMIm}] \mathrm{Cl})$ (60:40 mol\%) ionic liquid electrolyte. 


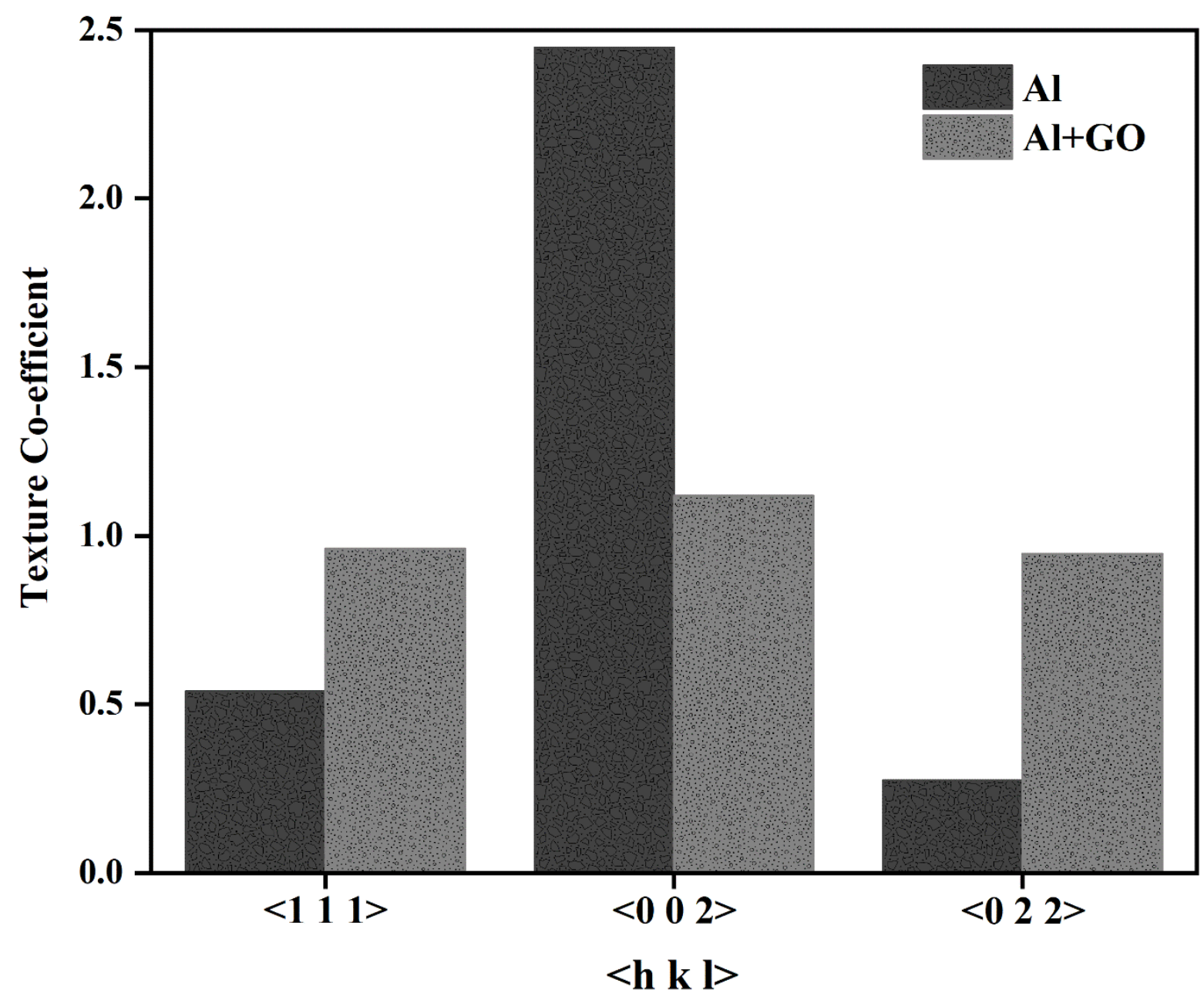

Fig. 5. Preferred orientation of aluminium crystallites in pure $\mathrm{Al}$ and $\mathrm{Al}-\mathrm{GO}$ composite coating. 


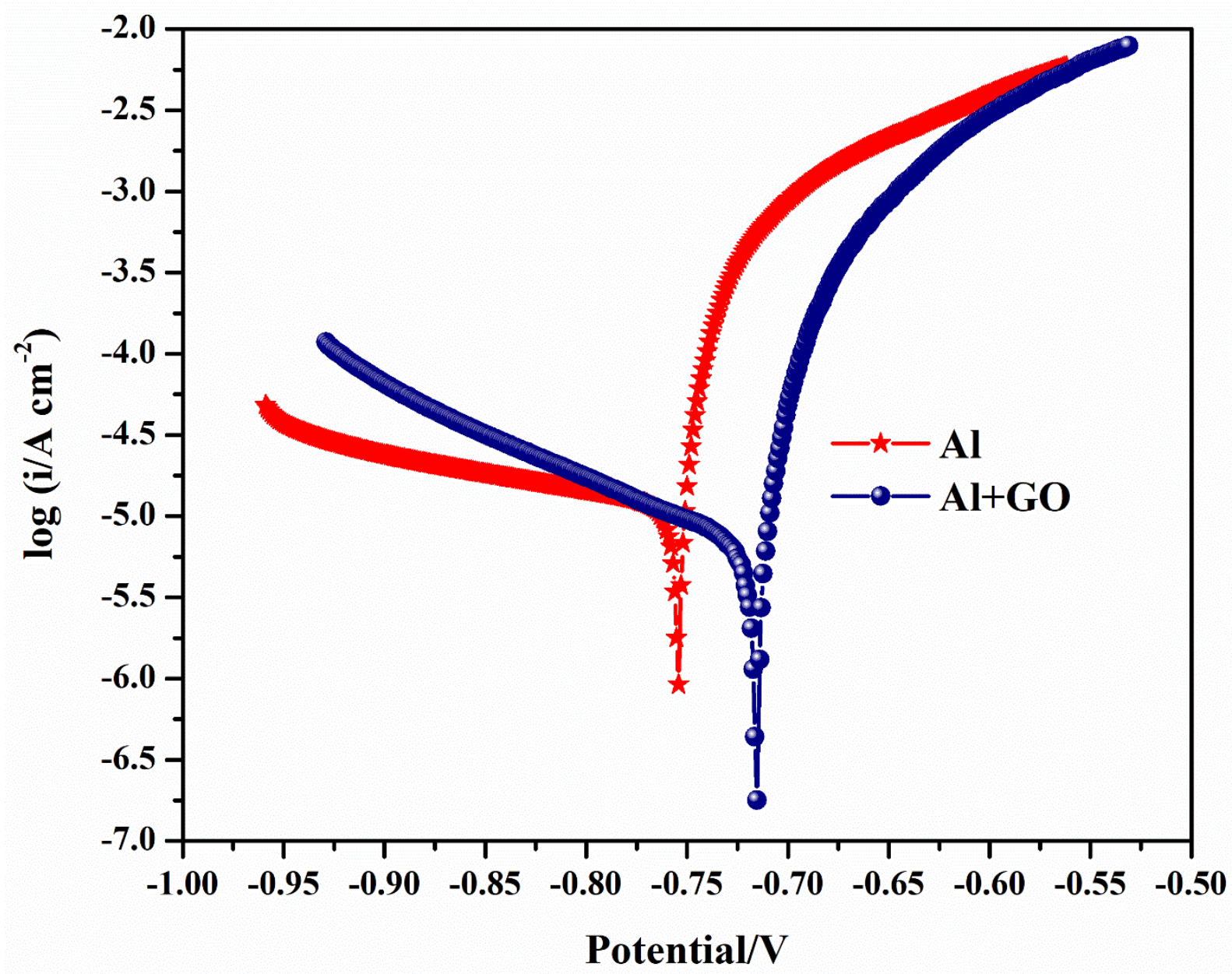

Fig. 6. Potentiodynamic polarization curves recorded for $\mathrm{Al}$ and Al-GO coatings against $\mathrm{Ag} / \mathrm{AgCl}$ reference electrode in $3.5 \% \mathrm{NaCl}$ electroactive media. 

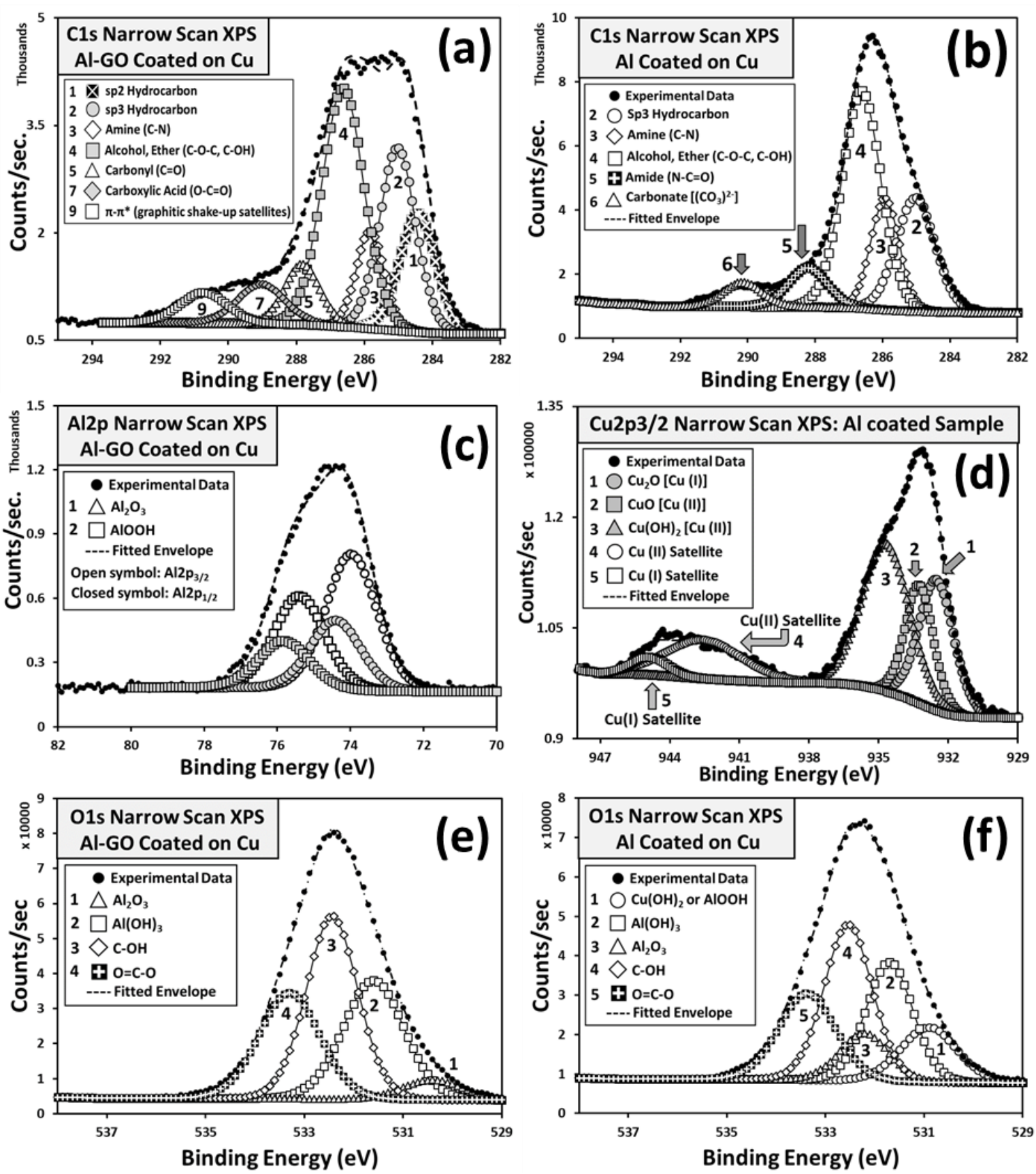

Fig. 7. Carbon 1s (C1s) narrow scan spectra of (a) $\mathrm{Al}$ and (b) Al-GO sample with legends showing the corresponding peak assignments. Al2p narrow scan spectra (c) of Al-GO sample shows the presence of $\mathrm{Al}_{2} \mathrm{O}_{3}$ and $\mathrm{AlOOH}$. All peak assignment references are from NIST (The National Institute of Standards and Technology, USA) Database, which can be accessed free off charge. 


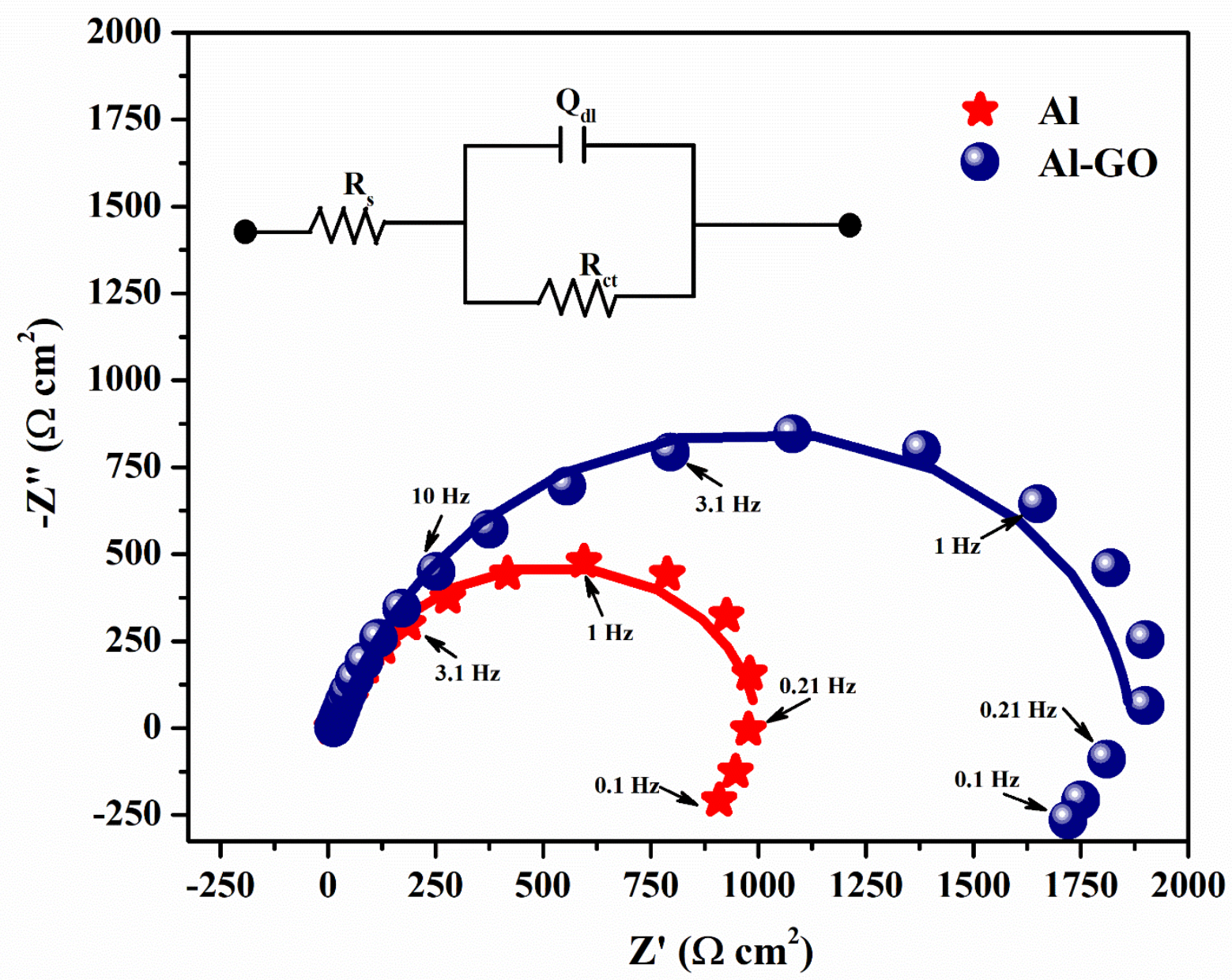

Fig. 8. Typical impedance Nyquist plots of $\mathrm{Al}$ and $\mathrm{Al}-\mathrm{GO}$ coatings recorded in $3.5 \% \mathrm{NaCl}$ corrosive media [symbol - measured data, line - simulated data]. The inset shows the electrical equivalent circuit used to simulate the EIS data to obtain electrochemical corrosion parameters. 


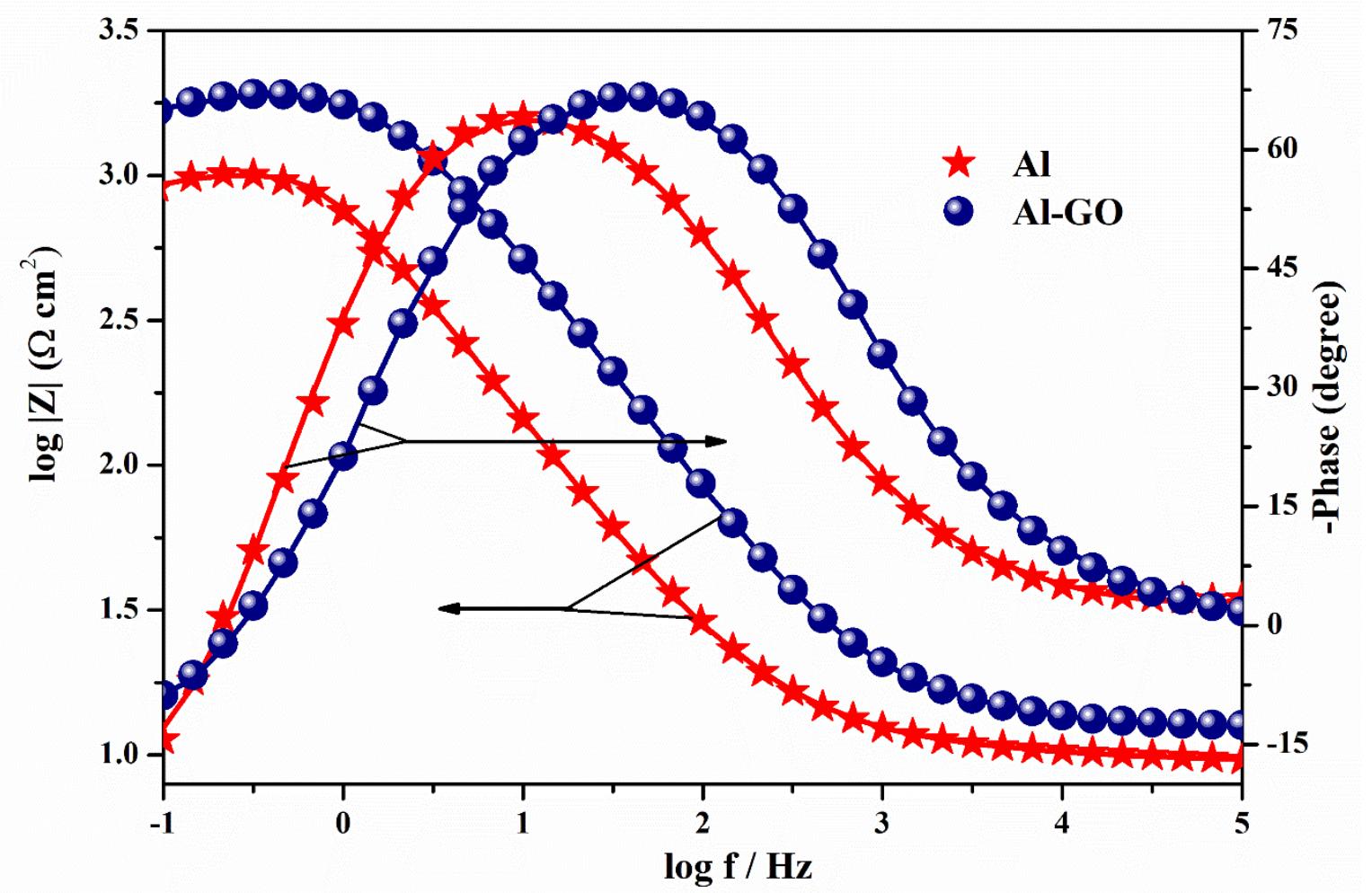

Fig. 9. EIS Bode, $\log |\mathrm{Z}| \&$ phase angle vs log frequency plots of $\mathrm{Al}$ and $\mathrm{Al}-\mathrm{GO}$ coatings. 
Table 1. Electrochemical corrosion parameters attained from Tafel polarization curves.

\begin{tabular}{cccccc}
\hline Sample & $\mathbf{E}_{\text {corr }} \mathbf{V}$ & $\begin{array}{c}\mathbf{I}_{\text {corr }} \\
\boldsymbol{\mu A ~ \mathbf { c m } ^ { - 2 }}\end{array}$ & $\begin{array}{c}\boldsymbol{\beta}_{\mathbf{a}} \\
\mathbf{m V} / \mathbf{d e c}\end{array}$ & $\begin{array}{c}\boldsymbol{\beta}_{\mathbf{c}} \\
\mathbf{m V} / \mathbf{d e c}\end{array}$ & $\mathbf{C R} \boldsymbol{\mu g} \mathbf{~ h r}^{-\mathbf{1}}$ \\
\hline Al & -0.754 & 24.38 & 169 & 473 & 8.18 \\
\multirow{2}{*}{ Al-GO } & -0.716 & 9.63 & 204 & 309 & 3.23 \\
\hline
\end{tabular}


Table 2. XPS survey scan data of two samples (Al and Al-GO) after corrosion.

\begin{tabular}{lcc}
\hline Element & Sample Al & Sample Al-GO \\
\hline Aluminium & 11.2 & 14.2 \\
Silicon & 4.8 & 0.0 \\
Chlorine & 0.8 & 1.2 \\
Carbon & 50.0 & 41.7 \\
Nitrogen & 1.2 & 0.8 \\
Oxygen & 30.9 & 42.0 \\
Copper & 1.2 & 0.0 \\
\hline
\end{tabular}


Table 3. Electrochemical corrosion data derived from EIS data simulation from electrical equivalent circuit.

\begin{tabular}{|c|c|c|c|}
\hline Sample & $\begin{array}{c}Q_{\text {dl }} \operatorname{in} 10^{-6} \\
\left(\Omega^{-1} \mathbf{c m}^{-2} S^{-n}\right)\end{array}$ & ndl & $\begin{array}{l}R_{\mathrm{ct} \text { in }} \\
\Omega \mathrm{cm}^{2}\end{array}$ \\
\hline $\mathrm{Al}$ & 194.7 & 0.83 & 987 \\
\hline Al-GO & 52.2 & 0.84 & 1859 \\
\hline
\end{tabular}

